\title{
Metachronous bilateral triple-negative breast cancer associated with neurofibromatosis type 1: A case report
}

\author{
YOJI YAMAGISHI ${ }^{1,2}$, TAKAHIRO EINAMA $^{2}$, TAMIO YAMASAKI ${ }^{2}$, TOMOMI KOIWAI $^{2}$, MIYUKI HIRATSUKA ${ }^{2}$, \\ MAKIKO FUKUMURA $^{2}$, TAKAKO KONO ${ }^{1}$, HIDEKI UENO ${ }^{2}$, JUNJI YAMAMOTO ${ }^{2}$ and HITOSHI TSUDA ${ }^{1}$
}

Departments of ${ }^{1}$ Basic Pathology and ${ }^{2}$ Surgery, National Defense Medical College, Tokorozawa, Saitama 359-8513, Japan

Received June 24, 2018; Accepted November 13, 2018

DOI: $10.3892 / \mathrm{ol} .2019 .9931$

\begin{abstract}
The present study reports a case of metachronous bilateral breast cancer associated with neurofibromatosis type 1 (NF1). A 67-year-old female, who had undergone a radical mastectomy of the left breast 34 years ago due to breast cancer, presented with a tumor of the right breast. The clinical stage of the original breast cancer was T2NOM0 stage IIA and adjuvant chemotherapy had not been not administered. With regard to the right-sided breast tumor, on physical examination, multiple neurofibromas and café-au-lait spots were found to be scattered over the skin. A 2-cm tumor was palpable. The preoperative histopathological diagnosis of the right-sided breast tumor was invasive ductal carcinoma, T2N0M0 stage IIA, with negative results for hormone receptors and human epidermal growth factor receptor 2 . The patient underwent a modified radical mastectomy and axillary node dissection, and received adjuvant chemotherapy. The bilateral tumors were similar in histology and immunophenotype, each being histological grade 3, triple-negative and with a basal-like subtype. Based on a literature review of 90 breast cancers in 84 patients with NF1 (84 patients, 90 breasts), younger age onset, advanced clinical stage and hormone receptor negativity were characteristic features. Bilateral cancer occurred in $8.3 \%$ of patients and was characterized by ER negativity, earlier stage and younger age compared with patients with unilateral cancer.
\end{abstract}

\section{Introduction}

Neurofibromatosis type 1 (NF1), also known as von Recklinghausen disease, is an autosomal dominant disorder that manifests as a number of symptoms, including pigmentary changes (café-au-lait spots, skin fold freckling and Lisch nodules) and neurofibromas (1). NF1 is known

Correspondence to: Dr Takahiro Einama, Department of Surgery, National Defense Medical College, 3-2 Namiki, Tokorozawa, Saitama 359-8513, Japan

E-mail: titiuehahaue@hotmail.com

Key words: neurofibromatosis type 1, von Recklinghausen disease, breast cancer to occur by heterozygous germ-line mutation of the NF1 gene, which is located on the pericentromeric region of the long arm of chromosome 17 and encodes the 327-kd protein known as neurofibromin $(2,3)$. The function of neurofibromin remains unknown. Patients with NF1 have an increased risk for the development of malignancies, particularly malignant peripheral nerve sheath tumors, optic and other glioma types, including cerebellar astrocytomas, ependymomas third-ventricle astrocytomas, cerebral astrocytomas, brain stem gliomas and spinal cord tumors, and leukemia and breast cancer (4). The characteristics of patients with breast cancer with NF1 have been reported to include negative estrogen receptor (ER), negative progesterone receptor (PgR), amplified human epidermal growth factor receptor 2 (HER2), higher tumor grade, and low 5-year survival rate compared with the control group (5). As the NF1 gene and the breast cancer susceptibility gene 1 ( $B R C A 1)$ DNA repair-associated gene are located on the long arm of chromosome 17, an association between the two genes has been reported (6).

The present study reports the case of a female patient who exhibited typical NF1 and was diagnosed with metachronous bilateral breast cancer. In addition, a literature review is presented of reported Japanese cases.

\section{Case report}

A 67-year-old female was referred to the National Defense Medical College Hospital (Saitama, Japan) due to a palpable lump in the right breast in December 2016. The past medical history of the patient included NF1 at the age of 25 years and a Halsted radical mastectomy for left-sided breast cancer (T2N0M0 stage IIA) at the age of 33 years. Following this original surgery, the patient did not receive adjuvant chemotherapy.

During the present physical examination, a $2-\mathrm{cm}$ tumor was palpated in the upper-outer quadrant of the right breast. The patient presented with classical NF1, indicated by neurofibromas over the trunk (Fig. 1). A high-density microlobulated mass with microcalcifications was observed in the right breast on a mammogram (Fig. 2). The mass was $1.8 \times 1.7 \mathrm{~cm}$ in size on ultrasound. Core needle biopsy specimens from the mass revealed invasive ductal carcinoma. Under the clinical diagnosis of T2N0M0 right-sided breast cancer, the patient underwent a modified radical mastectomy and sentinel node biopsy. As the sentinel node was intraoperatively 
diagnosed as positive for cancer, an axillary dissection was also performed.

The histopathological diagnosis of the surgically-resected specimens was invasive ductal carcinoma of no special type, nuclear grade 3 (Fig. 3A and B). The right-sided breast tumor was negative for ER, PgR and HER2. The Ki-67 labeling index was $26.5 \%$ (Fig. 3C-F). On histological review of the surgical specimens from the left-sided breast cancer obtained 34 years ago, the invasion range of the tumor was $5.0 \mathrm{~cm}$, and the tumor was diagnosed as an invasive, ductal, solid-tubular carcinoma, nuclear grade 3 (Fig. 4A and B). The pathological features of these bilateral types of breast cancer were similar. The left-sided breast cancer was also negative for ER, PgR and HER2, with a Ki-67 labeling index of $74.0 \%$ (Fig. 4C-F). The tumors were positive for the basal-like markers epidermal growth factor receptor (EGFR) and cytokeratin 5/6, and partially positive for vimentin. The patient is currently undergoing adjuvant therapy with epirubicin and cyclophosphamide, and treatment with docetaxel, with no evidence of recurrence in the 20 months following the most recent surgical treatment, according to the patient's 3 month follow-ups.

\section{Materials and methods}

Histological examination and immunohistochemistry. Histological examination was performed on the surgically-resected specimens fixed with $10 \%$ formalin for $24 \mathrm{~h}$ at room temperature. Paraffin-embedded sections (thickness, $4-\mu \mathrm{m})$ was performed using hematoxylin-eosin $(\mathrm{H} \& \mathrm{E})$ staining. For H\&E staining, sections were stained with $0.12 \mathrm{~g} / \mathrm{v} \%$ hematoxylin solution produced by Hematoxylin (C.I. 75290) cryst. (cat. no. 104302; Merck KGaA, Darmstadt, Germany) three times for $3 \mathrm{~min} / \mathrm{stain}$ at room temperature, and with eosin Y (cat. no. 058-00062; Wako Pure Chemical Industries, Ltd., Osaka, Japan) two times for $1.5 \mathrm{~min} / \mathrm{stain}$ at room temperature. The sections were treated with $5 \%$ hydrogen peroxide for $5 \mathrm{~min}$, followed by incubation with $0.4 \%$ block ace (cat. no. UK-B80; DS pharma, Japan) for $10 \mathrm{~min}$ at room temperature. The following commercially available primary antibodies were used: ER (cat. no. IR084; dilution, 1:100); PgR (cat. no. IR068; dilution, 1:100); HER2 (cat. no. A0485; dilution, 1:100); Ki-67 (cat. no. M7240); Cytokeratin 5/6 (CK5/6; cat. no. M7237; dilution, 1:50) and Vimentin (cat. no. M0725; dilution, 1:500; all Dako; Agilent Technologies, Inc., Santa Clara, CA, USA) at $4^{\circ} \mathrm{C}$ overnight, and subsequently incubated with Histofine Simplestain Max PO (cat. no. 424151; Nichirei Biosciences, Inc. Tokyo, Japan) as the secondary antibody for $1 \mathrm{~h}$ at room temperature. Immunohistochemical staining for EGFR was performed using the EGFR pharmDx ${ }^{\mathrm{TM}}$ kit (Dako; Agilent Technologies, Inc., Santa Clara, CA, USA). Sections were deparaffinized in three sequential xylene baths for $5 \mathrm{~min}$ at room temperature, $100 \%$ ethanol for $3 \mathrm{~min}$ and $95 \%$ ethanol for $3 \mathrm{~min}$, followed by a 5 -min single wash in wash-buffer solution (Dako; Agilent Technologies, Inc.). Subsequently, at room temperature, the section was rinsed in wash-buffer for $5 \mathrm{~min}$, incubated in proteinase $\mathrm{K}$ solution (Dako; Agilent Technologies, Inc.) for $5 \mathrm{~min}$, rinsed again in the wash-buffer for $5 \mathrm{~min}$, incubated in peroxidase blocking agent for $5 \mathrm{~min}$ at room temperature, rinsed, incubated with the primary EGFR antibody (clone 2-18C9, mouse monoclonal, prediluted) for $30 \mathrm{~min}$ at room temperature, rinsed,

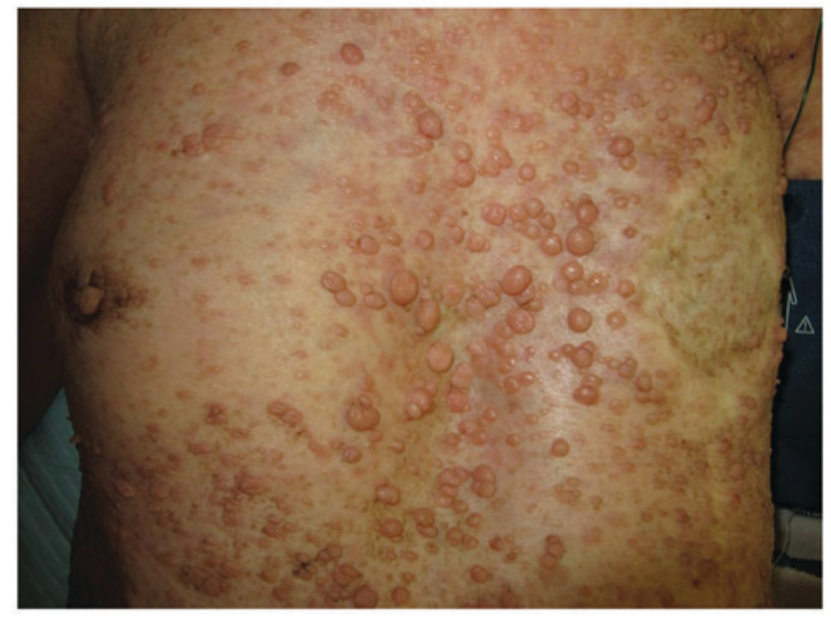

Figure 1. Multiple neurofibromas on the skin. The left-sided breast cancer was resected by radical mastectomy 35 years prior.

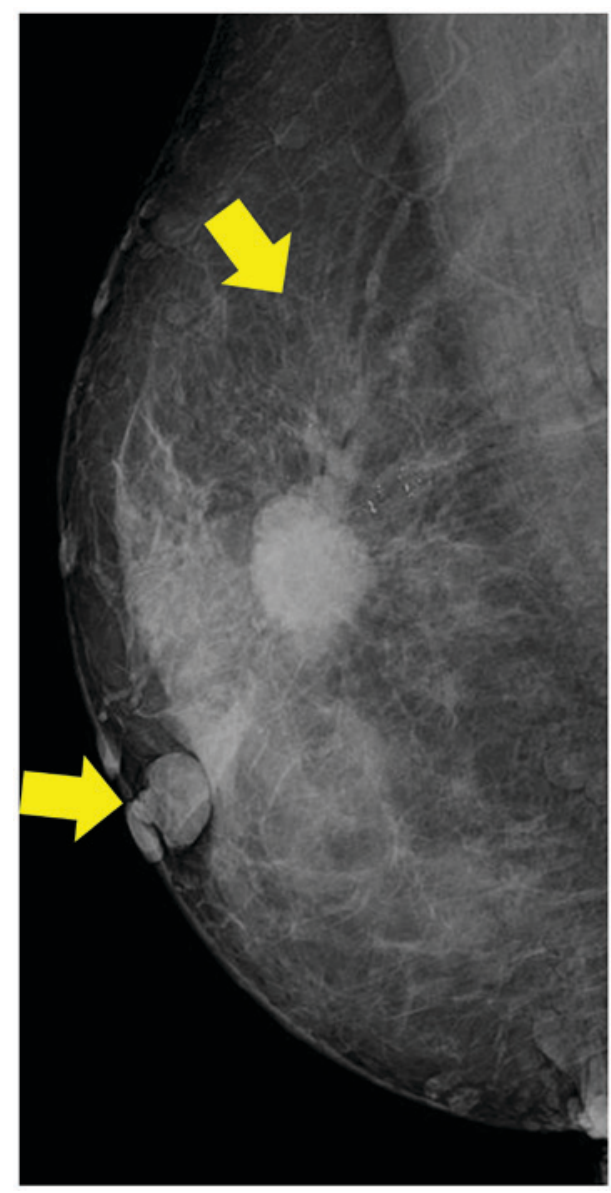

Figure 2. Mammogram of a 67-year old female patient, indicating a high-density microlobulated mass with microcalcifications and neurofibromas (Arrows)

incubated with visualization reagent for $30 \mathrm{~min}$, rinsed twice with the buffer, incubated with 3,3'-Diaminobenzidine for $5 \mathrm{~min}$ at room temperature and finally rinsed again with the buffer. Slides were counterstained with $0.12 \mathrm{~g} / \mathrm{v} \%$ hematoxylin solution produced by Hematoxylin cryst. (C.I. 75290; cat. no. 104302; Merck KGaA, Darmstadt, Germany) three times for $3 \mathrm{~min} / \mathrm{stain}$ at room temperature, and rinsed gently in 

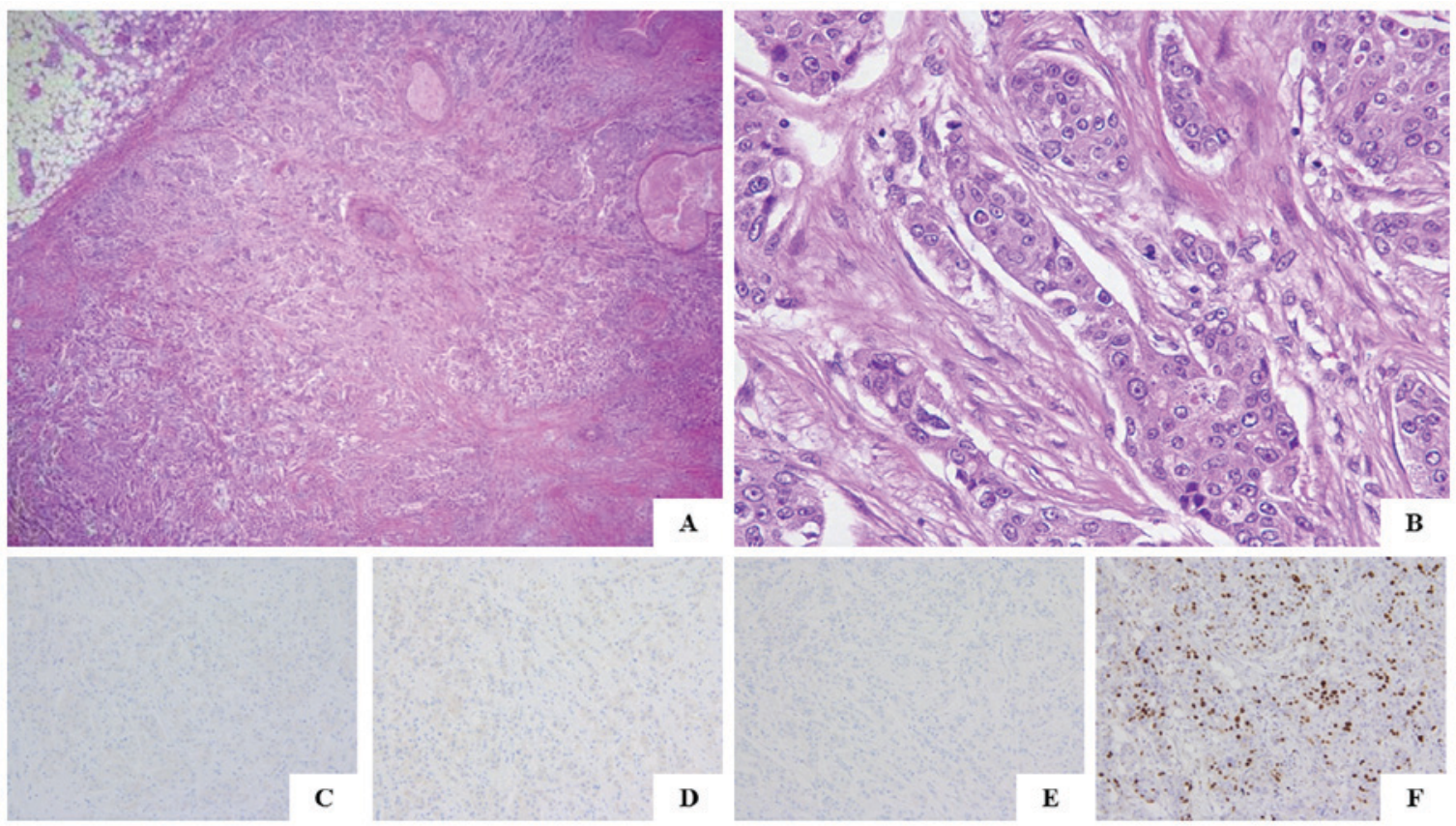

Figure 3. Histopathological features of the right-sided breast cancer. (A and B) The histological diagnosis was invasive ductal carcinoma, scirrhous carcinoma, grade 3, as observed by hematoxylin and eosin staining at magnification (A) x40 and (B) x400. Immunohistochemical features of (C) ER, (D) PgR and (E) HER2. Stains for ER, PgR and HER2 were all negative. (F) The Ki-67 labeling index was 26.5\% [(C-F) x200 magnification; immunoperoxidase staining]. ER, estrogen receptor; PgR, progesterone receptor; HER2 human epidermal growth factor receptor 2.
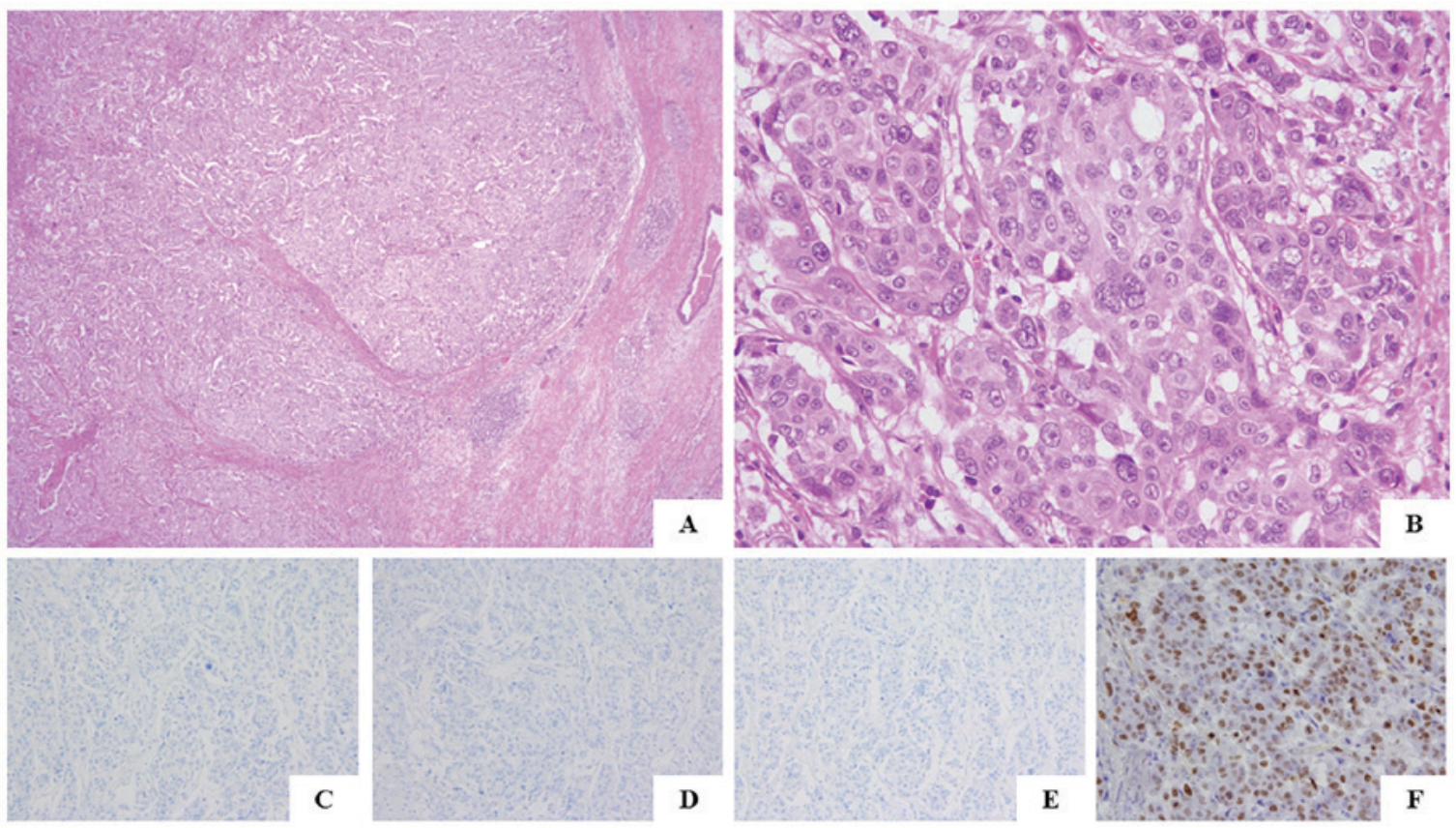

Figure 4. Histopathological features of the previous left-sided breast cancer. The histological diagnosis was invasive ductal carcinoma, solid-tubular carcinoma, grade 3, as observed by hematoxylin and eosin staining at magnification (A) x40 and (B) x400. Immunohistochemical features of (C) ER, (D) PgR and (E) HER2. ER, PgR and HER2 staining results were all negative. (F) The Ki-67 labeling index was 74.0\% [(C-F) magnification, x200; immunoperoxidase staining]. ER, estrogen receptor; PgR, progesterone receptor; HER2 human epidermal growth factor receptor 2.

reagent quality water. Slides were observed under a fluorescent microscope (magnification, $\mathrm{x} 40, \mathrm{x} 200$, and $\mathrm{x} 400$ ).

Histological study. ER and PgR were assessed by immunohistochemistry and defined as positive when $\geq 1 \%$ of constituent carcinoma cells were immunoreactive (7). Judgment of HER2 was made according to the American Society of Clinical
Oncology/College of American Pathologists guideline 2013 (8). Ki-67 was evaluated according to the recommendation of Breast Cancer Working Group (9). Histological diagnosis and pathological stage were determined by the clinical and pathological recording of breast cancer by Union for International Cancer Control (UICC) (10). 
Table I. Comparison of clinicopathological features between patients with breast cancer with neurofibromatosis type 1 (11) and patients with breast cancer surgically resected in Japan in 2015.

\begin{tabular}{|c|c|c|c|}
\hline Parameter & $\begin{array}{c}\text { NF1 patients } \\
(\mathrm{n}=84 ; \mathrm{n}=90 \text { affected breasts })\end{array}$ & $\begin{array}{c}\text { General population } \\
(\mathrm{n}=86,478 ; \mathrm{n}=86,478 \text { breasts })\end{array}$ & $\mathrm{P}$-value \\
\hline Laterality, n (\%) & & & 0.8532 \\
\hline Unilateral & 77 (91.7) & $78,173(90.4)$ & \\
\hline Bilateral & $7(8.3)$ & $8,305(9.6)$ & \\
\hline Age, years & & & $<0.0001$ \\
\hline Median, range & $53,25-88$ & 60 , unknown & \\
\hline$<35, \mathrm{n}(\%)$ & $10(11.9)$ & $1,579(1.8)$ & \\
\hline$\geq 35, \mathrm{n}(\%)$ & $72(85.7)$ & $84,775(98.0)$ & \\
\hline Unknown, n (\%) & $2(2.4)$ & $124(0.2)$ & \\
\hline UICC pStage, n (\%) (10) & & & $<0.0001$ \\
\hline $0, \mathrm{I}$ & $15(16.7)$ & $46,662(53.9)$ & \\
\hline II, III, IV & $61(67.8)$ & $37,334(43.2)$ & \\
\hline Unknown & $14(15.6)$ & $2,482(2.9)$ & \\
\hline Histological type, n (\%) & & & $<0.0001$ \\
\hline DCIS & $4(4.4)$ & $10,908(13.2)^{\mathrm{a}}$ & \\
\hline IDC & $58(64.4)$ & $59,941(72.3)^{\mathrm{a}}$ & \\
\hline Special type & $18(20.0)$ & $10,212(12.3)^{\mathrm{a}}$ & \\
\hline Unknown & $10(11.1)$ & $1,781(2.2)^{\mathrm{a}}$ & \\
\hline $\mathrm{ER}, \mathrm{n}(\%)$ & & & $<0.0001$ \\
\hline Positive & $14(15.6)$ & $60,768(73.4)^{\mathrm{a}}$ & \\
\hline Negative & $22(24.4)$ & $12,021(14.5)^{\mathrm{a}}$ & \\
\hline Unknown & $54(60.0)$ & $10,053(12.1)^{\mathrm{a}}$ & \\
\hline \multicolumn{4}{|l|}{ PgR, n (\%) } \\
\hline Positive & $11(12.2)$ & $52,997(64.0)^{\mathrm{a}}$ & $<0.0001$ \\
\hline Negative & $23(25.6)$ & $19,330(23.3)^{\mathrm{a}}$ & \\
\hline Unknown & $56(62.2)$ & $10,515(12.7)^{\mathrm{a}}$ & \\
\hline HER 2, n (\%) & & & $>0.999$ \\
\hline Positive & $1(1.1)$ & $9,817(11.9)^{\mathrm{a}}$ & \\
\hline Negative & $5(5.6)$ & $54,702(66.0)^{\mathrm{a}}$ & \\
\hline Unknown & $84(93.3)$ & $18,323(22.1)^{\mathrm{a}}$ & \\
\hline
\end{tabular}

aDenominator of 82,842 breast cancer cases. ER, estrogen receptor; PgR, progesterone receptor; HER2, human epidermal growth factor receptor 2; DCIS, ductal carcinoma in situ; IDC, invasive ductal carcinoma of no special type; UICC, Union for International Cancer Control.

Statistical analysis. A total of 90 previously reported cases of breast cancer in 84 Japanese patients with NF1 were assessed. Furthermore, the 90 cases of breast cancer associated with NF1 were compared with the 86,478 cases of the Breast Cancer Registry of the Japanese Breast Cancer Society in 2015 as a reference population (11). The compared parameters were laterality, age, UICC pStage, histological type, ER, PgR, HER2. A total of 82,842 patients without distant metastasis, histological type, ER, PgR, and HER2 were examined. The $\chi^{2}$ test or Fisher's exact test was used to determine the association between patients with NF1 and the general population, for bilateral and unilateral breast cancer, and other parameters, in patients with NF1. Differences were considered statistically significant when $\mathrm{P}<0.05$. All statistical analyses were performed using JMP ${ }^{\circledR}$ Pro 12 (SAS Institute Inc., Cary, NC, USA). Results are discussed in Tables I and II and the Discussion section.

\section{Discussion}

NF1 is an autosomal dominant genetic disorder caused by germline mutation of the NF1 gene, with an estimated birth incidence of 1 in 2,000-5,000 individuals (12). In total, 40,000 people are estimated to be affected in Japan (1). The diagnosis of NF1 is made based on the presence of $>6$ café-au-lait spots and multiple neurofibromas. In patients with NF1, half do not present with a family history, and therefore, the disease is considered to be caused by a de novo germline NF1 mutation (13).

Patients with NF1 have an increased risk of developing malignant peripheral nerve sheath tumors, optic and other gliomas, including cerebellar astrocytomas, ependymomas third-ventricle astrocytomas, cerebral astrocytomas, brain stem gliomas, and spinal cord tumors, and leukemia (4). 
Table II. Comparison of clinicopathological factors between bilateral breast cancer and unilateral breast cancer in patients with neurofibromatosis type 1 .

\begin{tabular}{|c|c|c|c|}
\hline Parameter & $\begin{array}{c}\text { Bilateral breast cancer } \\
(\mathrm{n}=7 ; \mathrm{n}=13 \text { affected breasts })\end{array}$ & $\begin{array}{c}\text { Unilateral breast cancer } \\
(\mathrm{n}=77 ; \mathrm{n}=77 \text { affected breasts })\end{array}$ & $\mathrm{P}$-value \\
\hline Age at first breast cancer, years & & & 0.1542 \\
\hline Median, range & 45, unknown & 53, unknown & \\
\hline$<35, \mathrm{n}(\%)$ & $2(28.6)$ & $8(10.4)$ & \\
\hline$\geq 35, \mathrm{n}(\%)$ & $4(57.1)$ & $68(88.3)$ & \\
\hline Unknown, n (\%) & $1(14.3)$ & $1(1.3)$ & \\
\hline UICC pStage, n (\%) (10) & & & 0.1178 \\
\hline $0, \mathrm{I}$ & $5(38.5)$ & $10(13.0)$ & \\
\hline II, III, IV & $8(61.5)$ & $53(68.8)$ & \\
\hline Unknown & $0(0)$ & $14(18.2)$ & \\
\hline Histological type, n (\%) & & & 0.1030 \\
\hline DCIS & $2(15.4)$ & $2(2.6)$ & \\
\hline IDC & $9(69.2)$ & $49(63.6)$ & \\
\hline Special type & $1(7.7)$ & $17(22.1)$ & \\
\hline Unknown & $1(7.7)$ & $9(11.7)$ & \\
\hline $\mathrm{ER}, \mathrm{n}(\%)$ & & & 0.0625 \\
\hline Positive & $0(0)$ & $14(18.2)$ & \\
\hline Negative & $6(46.2)$ & $16(20.8)$ & \\
\hline Unknown & $7(53.8)$ & $47(61.0)$ & \\
\hline PgR, n (\%) & & & 0.6379 \\
\hline Positive & $1(7.7)$ & $10(13.0)$ & \\
\hline Negative & $5(38.5)$ & $18(23.4)$ & \\
\hline Unknown & $7(53.8)$ & 49 (63.6) & \\
\hline HER 2, n (\%) & & & $>0.9999$ \\
\hline Positive & $0(0)$ & $1(1.3)$ & \\
\hline Negative & $2(15.4)$ & $3(3.9)$ & \\
\hline Unknown & $11(84.6)$ & $73(94.8)$ & \\
\hline
\end{tabular}

ER, estrogen receptor; PgR, progesterone receptor; HER2, human epidermal growth factor receptor 2; DCIS, ductal carcinoma in situ; IDC, invasive ductal carcinoma of no special type; UICC, Union for International Cancer Control.

Epidemiological studies have demonstrated that patients with NF1 are 4-times more likely to develop malignant tumors compared with the general population $(14,15)$. Furthermore, the risk of breast cancer in younger patients with NF1 $(<50$ years old) has been reported to be 2.68- to 4.9-times higher compared with that in the general population (16-18). Screening mammography is recommended for women $\geq 40$ years old who are affected by NF1 (16). The number of ductal carcinoma in situ (DCIS) cases has risen with the recent increase in breast cancer screening. Uusitalo et al (5) reported that 32 out of 1,404 patients with NF1 were diagnosed with breast cancer. In this study, the characteristics of patients with breast cancer with NF1 included negative ER, negative PgR and amplified HER2 results, higher tumor grade and a low 5-year survival rate (68.1\% in patients with NF1 vs. $82.0 \%$ in the control group).

A total of 90 previously reported cases of breast cancer in 84 Japanese patients with NF1 were assessed (Table I) (11). In one case of bilateral breast cancer, the details of the initial breast cancer were unknown. The mean age of these patients with breast cancer was 52.6 years (range, 25-88 years). Only in one case was the patient male. The rate of bilateral breast cancer was $8.3 \%$ (7/84). When the 90 cases of breast cancer associated with NF1 were compared with the 86,478 cases of breast cancer resected in Japan in 2015 as a reference population, the NF1-associated breast cancers were characterized by a younger age $(\mathrm{P}<0.0001)$, a more advanced clinical stage $(\mathrm{P}<0.0001)$, and ER and $\mathrm{PgR}$ negativity $(\mathrm{P}<0.0001)$. Among the patients with breast cancer associated with NF1, the percentage of patients $<35$ years was $11.9 \%$, which was higher compared with that in the reference group (1.8\%). Nakamura et al (19) similarly reported that the rate of patients with breast cancer and NF1 who were $\leq 35$ years was $18.5 \%$. Among the 90 cases of breast cancer, only $16.7 \%(15 / 90)$ were diagnosed as early-stage breast cancer (UICC; stage 0 or I). Therefore, the majority of cases were diagnosed at stage II or at a more advanced stage. Murayama et al (20) considered that breast tumors were overlooked until they increased in size due to the symptoms of systemic neurofibromatosis. In the present case, only following an extensive amount of time ( 2 years) did the patient realize that the breast tumor may be different from a skin tumor. In addition, the present case verified that another 
characteristic of NF1-associated breast cancer is ER $(22 / 36$, $61.1 \%)$ and $\operatorname{PgR}(23 / 34,67.6 \%)$ negativity. With regard to HER2, Uusitalo et al (5) reported that HER2 was positive in $30.8 \%$ of NF1-associated breast cancers. However, in the present literature review, the HER2-positive rate was only $16.7 \%$ (1/6).

Following the division of the 84 patients into two groups representing unilateral and bilateral cancer, it was observed that the clinicopathological characteristics slightly differed. The rate of ER-negative tumors was higher among the bilateral NF1 cases compared with that among the unilateral NF1 cases (100\% vs. $53 \%$; $\mathrm{P}=0.063$ ), although there was no statistical difference. Likewise, bilateral cases had a higher percentage of stage 0 or I breast cancer, DCIS and patients $<35$ years old compared with unilateral cases, although these results were not statistically significant (Table II). There was no significant difference in PgR or HER2 status between the unilateral and bilateral groups.

The NF1 gene is located on the pericentromeric region of the long arm of chromosome 17. This gene encodes neurofibromin, which is composed of 59 exons, spanning $350 \mathrm{kD}$ of genomic DNA; it inhibits Ras activity by facilitating the conversion of active Ras-GTP to inactive Ras-GDP (21).

The NFI and BRCAl genes are located on the long arm of chromosome 17 , and are topologically relatively close to each other with a genetic distance of $20 \mathrm{cM}$. Ceccaroni et al (6) reported that two linked mutations at NFI and BRCAI caused concurrent $N F 1$, and hereditary breast and ovarian cancer (HBOC) in the same family. In addition, previous reports have examined single germline mutations in NFI and $B R C A 1$ genes in the same individual $(22,23)$. In these reports, examination of a $B R C A 1$ gene mutation as an early screening method for patients with NF1 was indicated to aid the early detection of breast cancer, thus reducing morbidity and mortality rates.

In the National Comprehensive Cancer Network guidelines for genetic/familial high-risk assessment of breast and ovarian cancer, detailed genetic risk assessment is recommended for patients $\leq 50$ years old, for patients $\leq 60$ years old with triple-negative breast cancer and for patients with a history of two primary types of breast cancer (24). Based on the aforementioned criteria, the present patient had a high genetic risk for HBOC, and genetic testing for $B R C A 1 / 2$ may have been beneficial for early detection of the second breast cancer.

In summary, the present study reports the case of an NF1 patient with metachronous bilateral breast cancer. The two breast cancers were diagnosed as triple-negative and basal-like subtype by immunohistochemistry. Based on a literature review of 84 patients, a younger age onset, an advanced clinical stage and hormone receptor negativity were indicated to be characteristic features of breast cancer in patients with NF1.

\section{Acknowledgements}

Not applicable.

\section{Funding}

The present study was supported in part by a grant-in-aid for defense medicine from the Ministry of Defense and a grant-in-aid from the Foundation for Promotion of Defense Medicine.

\section{Availability of data and materials}

The findings used and/or analyzed during this published article are available from the corresponding author on reasonable request.

\section{Authors' contributions}

YY, TE and HT collaborated in the conception and design of the study. YY, TY, ToK, MH, MF, and TaK acquired the data. YY, TE, TY, ToK, MH, MF, TaK, HU, JY and HT performed data analysis and interpretation. All authors were involved in writing the manuscript. All authors read and approved the final manuscript.

\section{Ethics approval and consent to participate}

Not applicable.

\section{Patient consent for publication}

Written informed consent was provided by the patient for publication of this study.

\section{Competing interests}

The authors declare that they have no competing interests.

\section{References}

1. Yoshida Y, Kuramochi A, Ohta A, Furumura M, Imafuku S, Matsuo M, Chikuda H, Funasaki H, Saito K, Saya H, et al: Diagnostic criteria and treatment guidelines for nerve fibrosis type 1 (Recklinghausen's disease). Jpn J Dermatol 118: 1657-1666, 2008 (In Japanese).

2. Wallace MR, Marchuk DA, Andersen LB, Letcher R, Odeh HM, Saulino AM, Fountain AM, Brereton A, Nicholson J and Mitchell AL: Type 1 neurofibromatosis gene: Identification of a large transcript disrupted in three NF1 patients. Science 249: 181-186, 1990.

3. Gottfried ON,Viskochil DHandCouldwellWT:Neurofibromatosis Type 1 and tumorigenesis: Molecular mechanisms and therapeutic implications. Neurosurg Focus 28: E8, 2010.

4. Korf BR: Malignancy in neurofibromatosis type 1 . Oncologist 5: 477-485, 2000.

5. Uusitalo E, Kallionpää RA, Kurki S, Rantanen M, Pitkäniemi J, Kronqvist P, Härkönen P, Huovinen R, Carpen O, Pöyhönen $\mathrm{M}$, et al: Breast cancer in neurofibromatosis type 1: Overrepresentation of unfavourable prognostic factors. Br J Cancer 116: 211-217, 2017.

6. Ceccaroni M, Genuardi M, Legge F, Lucci-Cordisco E, Carrara S, D'Amico F, Greggi S and Scambia G: BRCA1-related malignancies in a family presenting with von recklinghausen's disease. Gynecol Oncol 86: 375-378, 2002.

7. Hammond ME, Hayes DF, Dowsett M, Allred DC, Hagerty KL, Badve S, Fitzgibbons PL, Francis G, Goldstein NS, Hayes M, et al: American society of clinical oncology/college of american pathologists guideline recommendations for immunohistochemical testing of estrogen and progesterone receptors in breast cancer. Arch Pathol Lab Med 134: 907-922, 2010

8. Wolff AC, Hammond ME, Hicks DG, Dowsett M, McShane LM, Allison KH, Allred DC, Bartlett JM, Bilous M, Fitzgibbons P, et al: Recommendations for human epidermal growth factor receptor 2 testing in breast cancer: American Society of Clinical Oncology/College of American Pathologists clinical practice guideline update. J Clin Oncol 31: 3997-4013, 2013.

9. Dowsett M, Nielsen TO, A'Hern R, Bartlett J, Coombes RC, Cuzick J, Ellis M, Henry NL, Hugh JC, Lively T, et al: Assessment of Ki67 in breast cancer: Recommendations from the international Ki67 in breast cancer working group. J Natl Cancer Inst 103: 1656-1664, 2011. 
10. Brierley JD, Gospodarowicz MK, Wittekind C (eds): TNM Classification of Malignant Tumours. 8th ed. Wiley-Blackwell, Chichester, 2017

11. Salemis NS, Nakos G, Sambaziotis D and Gourgiotis S: Breast cancer associated with type 1 neurofibromatosis. Breast Cancer 17: 306-309, 2010

12. Rasmussen SA and Friedman JM:NF1 gene and neurofibromatosis 1. Am J Epidemiol 151: 33-40, 2000.

13. Takano T, Kawashima T, Yamanouchi Y, Kitayama K, Ueno K and Hamaguchi H: Genetics of neurofibromatosis 1 in Japan: Mutation rate and paternal age effect. Hum Genetics 89: 281-286, 1992.

14. Sorensen SA, Mulvihill JJ and Nielsen A: Long-term follow-up of von Recklinghausen neurofibromatosis. Survival and malignant neoplasms. N Engl J Med 314: 1010-1015, 1986.

15. Zoller ME, Rembeck B, Oden A, Samuelsson M and Angervall L: Malignant and benign tumors in patients with neurofibromatosis type 1 in a defined Swedish population. Cancer 79: 2125-2131, 1997.

16. Sharif S, Moran A, Huson SM, Iddenden R, Shenton A, Howard E and Evans DG: Women with neurofibromatosis 1 are at a moderately increased risk of developing breast cancer and should be considered for early screening. J Med Genet 44: 481-484, 2007.

17. Walker L, Thompson D, Easton D, Ponder B, Ponder M, Frayling I and Baralle D: A prospective study of neurofibromatosis type 1 cancer incidence in the UK. Br J Cancer 95: 233-238, 2006.

18. Madanikia SA, Bergner A, Ye X and Blakeley JO: Increased risk of breast cancer in women with NF1. Am J Med Genet A 158a: 3056-3060, 2012 ..

19. Nakamura M, Tangoku A, Kusanagi H, Oka M and Suzuki T: Breast cancer associated with Recklinghausen's disease: Report of a case. Nihon Geka Hokan 67: 3-9, 1998.
20. Murayama Y, Yamamoto Y, Shimojima N, Takahara T, Kikuchi K, Iida S and Kondo Y: T1 Breast cancer associated with von recklinghausen's neurofibromatosis. Breast Cancer 6: 227-230, 1999.

21. Xu GF, Lin B, Tanaka K, Dunn D, Wood D, Gesteland R, White R, Weiss R and Tamanoi F: The catalytic domain of the neurofibromatosis type 1 gene product stimulates ras GTPase and complements ira mutants of S. cerevisiae. Cell 63: 835-841, 1990.

22. Jeon YW, Kim RM, Lim ST, Choi HJ and Suh YJ: Early-onset breast cancer in a family with neurofibromatosis type 1 associated with a germline mutation in BRCA1. J Breast Cancer 18: 97-100, 2015.

23. Campos B, Balmana J, Gardenyes J, Valenzuela I, Abad O, Fàbregas P, Volpini V and Díez O: Germline mutations in NF1 and BRCA1 in a family with neurofibromatosis type 1 and early-onset breast cancer. Breast Cancer Res Treat 139: 597-602, 2013.

24. Daly MB, Pilarski R, Berry M, Buys SS, Farmer M, Friedman S, Garber JE, Kauff ND, Khan S, Klein C, et al: NCCN Guidelines insights: Genetic/familial high-risk assessment: Breast and ovarian, version 2.2017. J Natl Compr Canc Netw 15: 9-20, 2017.

(i) () () This work is licensed under a Creative Commons Attribution-NonCommercial-NoDerivatives 4.0 International (CC BY-NC-ND 4.0) License. 